\title{
Educación Física post COVID-19 ¿Evolución o deriva?
}

\section{Post COVID-19 Physical Education ¿Evolution or drift?}

\author{
Bienvenido Martínez Egea \\ Universidad Pablo de Olavide \\ bmarege@upo.es
}

\section{Situación de partida. ¿De dónde venimos?}

Como en todas las grandes crisis, esta pandemia mundial provocada por la COVID-19 ha zarandeado creencias y hábitos de vida que creíamos inamovibles. El cierre de colegios, institutos y universidades ha vuelto a demostrar, con más virulencia que nunca, un hecho relevante que no terminamos de comprender, a saber, que el sistema educativo imperante es anacrónico. Anclado en la misma estructura de hace más de cien años, este sistema que hoy mantenemos fue creado para que las personas adquirieran las destrezas con las que incorporarse al mercado laboral, y continúa generalmente manteniendo sentado al alumnado durante muchas horas al día, transmitiéndoles ideas y conceptos de forma acrítica y repetitiva. La experiencia recién vivida a costa de la crisis sanitaria del coronavirus no ha hecho más que desenmascarar esta realidad a través de la enseñanza telemática desde el confinamiento.

En el área de la educación física y deportiva se ha experimentado un recorrido similar, aunque agravada por una utilización tradicional del cuerpo y el movimiento al servicio de un modelo instruccional más parecido a una formación militar que educativa, y estigmatizada por profundas creencias religiosas que denostaban la expresión corporal y la relación del alumnado con su propio cuerpo, constriñendo con prejuicios y estereotipos desde la psicomotricidad hasta el comportamiento de los niños y niñas de acuerdo con su sexo (Bourdieu, 1992; Sánchez y Moscoso, 2015). De acuerdo con ello, podemos hablar también de una "gimnasia anacrónica", basada en movimientos mecánicos y repetitivos, que no hacen más que contribuir a la socialización del individuo conforme a las normas de convención social y pensando en lograr la sumisión del individuo a los valores imperantes en nuestra sociedad, según García Ferrando (1998: 25), "[...] el deporte constituye un refuerzo positivo e ideológico del que se vale el sistema capitalista para conseguir en la masa social un aquiescencia moral y fáctica que hace posible que las relaciones de dominación y poder sigan inalterables". Y es que, según Brohm, el modelo deportivo imperante desde el siglo XVIII "constituye la reproducción de los valores de la sociedad capitalista funcionando como una superestructura ideológica positiva (es la institución del reino de la positividad), neutra (nunca llega a cuestionar el orden establecido), integradora (es un modo de comportamiento, un modelo social ideológicamente valorizado) y ritual (se ha convertido en el ámbito de la mitología profana auspiciado por los mass media), objeto de un gran consumo que hace éste sea vivido como una cultura cotidiana (1982: 97). 
Frente a ello, hoy también existe una corriente amplia de educadores y educadoras físicas que se encuentra muy alejada de ese canon gimnástico y del cuerpo que tradicionalmente se ha impuesto. Además de promover hábitos de vida saludable mediante el fomento de una actividad física regular, también ha ido tomando fuerza la concepción de la Educación Física como elemento socializador crítico y empático, con el que perseguir el crecimiento y desarrollo personal. La educación en valores a través del movimiento va tomando cada vez más espacio, tiempo y dedicación entre el profesorado de esta especialidad. Y su buen hacer se multiplica de manera exponencial cuando se trabaja desde equipos y perspectivas multidisciplinares.

Las personas responsables de las escuelas deportivas también van siendo cada vez más sensibles y conscientes de la necesidad de priorizar la formación de la persona y el gozo psicológico de la experiencia de la práctica deportiva frente al logro de resultados basados en el mero rendimiento físico y técnico. En España, hace unas décadas bastaba haber practicado un deporte para creerse merecedor del título de entrenador deportivo. Hoy son muchos los practicantes de deporte que reclaman un modelo de deporte base que contribuya a su bienestar y mejora de salud, y a garantizar el disfrute de las relaciones sociales, frente a la persecución del logro en competición. Resulta muy esperanzador comprobar que frente a sistemas competitivos y excluyentes, se potencian, cada vez más verdaderas escuelas deportivas en las que la colaboración y la inclusión pueden ser referente de una sociedad más humanista. Desde esta perspectiva, el deporte debe estar al servicio del disfrute y el desarrollo de las niñas y los niños, y no al revés.

\section{Planteamiento crítico de la situación actual. ¿Y dónde nos encontramos ahora?}

Si entendemos los conflictos como fenómenos naturales en la vida, en lugar de verlos como peligros que amenazan nuestra comodidad, la situación que está dibujando esta emergencia sanitaria mundial puede ayudar a replantearnos los principios pedagógicos dominantes en el ámbito de la educación físico-deportiva. Los conflictos resultan imprescindibles para generar cambios.

Parece que ha habido una sensación generalizada de incertidumbre entre el profesorado de todos los niveles educativos. Tras el cierre de los centros escolares y durante el estado de alarma, muchos educadores y educadoras han sufrido un sentimiento de abandono por parte de la administración educativa.
Es justo reconocer que esta situación no era previsible y, por tanto, que también los responsables de la gestión de las políticas públicas careciesen de mayor capacidad de respuesta y, sobre todo, de una respuesta diligente y estructural eficaz. Sea como fuere, la sensación vivida por el profesorado ha sido la del abandono a su suerte, una especie de "ahí lo lleváis, apañaros como podáis", echando en falta instrucciones menos ambiguas, por no hablar de más recursos para hacer frente a una situación tan excepcional como la vivida.

La situación y, en particular, la incertidumbre experimentada, ha dejado descolocado también al cuerpo de docentes de Educación Física. Ante la dificultad de transmitir nuestra labor esencial, especialistas de los diferentes niveles nos ocupamos, en un primer momento, de proponer actividades que garantizaran un mínimo de actividad física corporal entre el alumnado confinado, acorde a las recomendaciones sanitarias que se establecieron desde el inicio. Y en una segunda fase en la que se produjo un intercambio de recursos y experiencias entre el profesorado del área de Educación Física, se propusieron la propuesta de actividades en forma de desafíos que propiciaran la recuperación de actividades más lúdicas y atractivas para el alumnado, las cuales, a su vez, proporcionaran momentos de esparcimiento y ocio activo desde el confinamiento de sus hogares.

sin embargo, después de la experiencia vivida estos meses de atrás, deberíamos realizar algunas reflexiones críticas de aquello que hemos denominado Educación Física desde casa:

Para comenzar, parece seguir predominando aún entre la comunidad de docentes de Educación Física un cierto complejo de inferioridad frente a otras materias curriculares. Una parte importante del profesorado del área parecía mostrar reparos en el envío de tareas de la materia, alegando no querer sobrecargar al alumnado, porque este ya estaba desbordado con actividades de otras asignaturas. Sin duda que la intención era cuidar a nuestros chicos y chicas. Pero precisamente era durante el confinamiento en los hogares cuando el alumnado más necesitaba jugar, moverse y liberarse. En ese sentido, quizá no estuvimos a la altura. Si de verdad hubiéramos pensado en cuidarlos, puede que debiéramos haber exigido con más contundencia al resto de profesorado que rebajara el exceso generalizado en la carga de trabajo que les impusieron.

En muchos casos se ha recurrido a animar al alumnado a practicar actividad física mediante vídeos populares o canales de redes sociales de dudoso rigor profesional. Por respeto a las luchas de nuestro colectivo durante años, en las que se exigió la regu- 
lación del sector profesional en centros y gimnasios deportivos, garantizando la existencia de monitores formados, y requiriendo la supervisión de profesionales titulados en ciencias de la actividad física y el deporte, no es admisible ahora confiar la seguridad y la salud del alumnado a cualquier "influencer" que reciba millones de visitas con sus vídeos de fitness. Antes hay que asegurarse que esas prácticas son dirigidas o revisadas por profesionales del sector.

Propuesta de actividades teóricas exclusivas. En algunos casos, se ha confundido la finalidad con los medios. En ningún caso la educación física puede estar basada predominantemente en actividades teóricas, ni siquiera en una situación excepcional de confinamiento en casa. Eso no es Educación Física. No podemos cometer el error de querer alcanzar el falso estatus de otras asignaturas "importantes", cometiendo los mismos errores pedagógicos de los que abusan muchas otras asignaturas y, por lo demás, porque no son asignaturas homólogas, pues difieren por su especificidad, contenido y finalidad.

A pesar de las dificultades, deberíamos revisar también las propuestas educativas que se han lanzado. Muchas de estas actividades físicas han estado enmascaradas en el atractivo de las nuevas tecnologías, pero no llegan a alcanzar la esencia de los aprendizajes pretendidos. Si algo caracteriza a nuestra asignatura es su carácter vivencial y la búsqueda constante del máximo compromiso motor en las clases de Educación Física.

Por último, reconocer y aceptar nuestra frustración como educadores y educadoras. A pesar del sacrificio extenuante llevado a cabo por la inmensa mayoría de docentes, no siempre hemos logrado alcanzar los objetivos mínimos planteados mediante las actividades telemáticas. Lo más relevante es haber aprendido en el proceso de búsqueda y puesta en práctica de los planteamientos educativos a distancia.

\section{$3^{\circ}$ Retos ¿Hacia dónde vamos?}

La educación en su conjunto seguirá afectada desde el inicio del curso escolar 2020/2021. No sabemos todavía cómo se organizará la labor educativa. Pero en Educación Física esos cambios que nos esperan a la vuelta del verano pueden ser de magnitud preocupante. Existen dudas de si se podrán utilizar balones u otros materiales básicos para desarrollar juegos y actividades grupales. Ni siquiera sabemos si podremos realizar juegos tan básicos como el pilla-pilla $u$ otras actividades físicas que impliquen el más mínimo contacto. ¿Podremos llamar de verdad "Educación Física" a lo que nos toque afrontar en la vuelta al cole? El reto que tenemos por delante el profesorado de Educación Física, así como el resto de técnicos deportivos de base, es monumental.

En este nuevo escenario que se nos plantea, lo que está claro es que tendremos que aprender a convivir con la incertidumbre de aplicar proyectos educativos muy alejados del escenario ideal. Sin embargo, muchos expertos aseguran ya que exigir medidas estrictas solo en los centros educativos no será útil, sobre todo cuando en otros sectores sociales y económicos se han regulado muchas medidas de flexibilidad. Hay incluso quienes aseguran que la crisis sanitaria resulta la excusa perfecta para que algunos agentes estructurales asuman un mayor control a su antojo de nuestro modelo social. También se está hablando de recortes en educación pública, cuando en estas situaciones de crisis salen en mejores condiciones quienes más han invertido en educación e innovación. Más que el cierre masivo de centros educativos, o la prohibición de que podamos poner en práctica actividades que impliquen cualquier acercamiento físico, parece que habrá que replantearse otras cuestiones. ¿Qué podemos hacer las personas que nos dedicamos a la formación físico-deportiva? Pues de momento compartir experiencias y generar debates públicos en los que plantear la utilidad y la eficacia de recursos para resolver los grandes retos que tenemos por delante. Aquí van algunas cuestiones que pueden invitar a la reflexión-acción.

1. Mirar atrás e inspirarnos en los grandes pedagogos. Antes de echar a andar, quizá deberíamos volver a leer a aquellos que plantearon las grandes invariantes pedagógicas (Freire, Giner de los Ríos, Freinet, Ferrer y Guardia, etc.). Es decir, quienes en su día descubrieron que hay principios educativos que no pasan de moda, que permanecen y sobreviven incluso en estos tiempos de incertidumbre.

2. El Aprendizaje Cooperativo puede ser una de las claves en el cambio de paradigma educativo que ya se viene plasmando desde hace años en la Educación Física. Frente a una sociedad en la que se han impuesto valores de corte individualista y competitivo, el aprendizaje cooperativo ayuda a vislumbrar un horizonte donde el valor del grupo, la empatía, la cooperación, la responsabilidad y la solidaridad muestran un camino a seguir. Los desafíos cooperativos pueden ser un buen punto de partida para descubrir un modelo realmente transformador.

3. ¿Nuevas tecnologías o buenas tecnologías? Nos desborda la tecnología educativa, pero deberíamos pensar más en cómo ésta puede contribuir a la labor pedagógica. "Temo el día en el que la tecnología supere a la humanidad, porque ese día tendremos una generación de idiotas". Esta cita atribuida a Al- 
bert Einstein puede ser toda una llamada de atención en estos tiempos en los que hay quienes confían toda su suerte en la educación a distancia, especialmente en Educación Física. A este respecto, no hemos de ignorar los peligros como la brecha digital, o hándicaps como la conciliación familiar, para el adecuado cumplimiento de servicios públicos como la educación a través del uso de las tecnologías.

4. La Pedagogía vivencial no es negociable en el área de Educación Física, es un elemento esencial en la misma. Expertos en neuroeducación aseguran que todo el currículo educativo debería articularse en torno a tres áreas fundamentales, entre las que se encuentra la Educación Física, ya que implica los aprendizajes más transversales que podemos encontrar. Mediante el ejercicio físico entrenamos partes del cerebro fundamentales para el correcto desarrollo del individuo.

5. Nada de lo que se ha planteado en este artículo sería posible si no respetamos los principios básicos de la verdadera escuela inclusiva, en la cual todos y todas tengan las mismas oportunidades. Más que de igualdad, hablamos de equidad. Por eso corresponde defender especialmente la educación pública como garante de una sociedad plural y justa. Excusándose en la búsqueda de una mayor objetividad, la tendencia actual es potenciar los estándares evaluables, los criterios de evaluación por objetivos, así como los test estandarizados, también en Educación Física.

6. Por último, se cree igualmente en la necesidad de hacer de la Educación Física una herramienta humanista, recurriendo a las propuestas que abordan la educación en valores como eje vertebrador de una formación integral. Deberíamos aprovechar la riqueza que se nos brinda para potenciar y desarrollar valores como cooperación, autosuperación, autoestima, respeto, diálogo, creatividad o tolerancia. E igualmente hacer de la Educación Física una herramienta para la formación de la paz. Colectivos como La Peonza llevan años trabajando la regulación de conflictos y la convivencia positiva en las clases de educación física. La filosofía del "Fair Play" y los valores positivos del deporte también contribuyen a potenciar una sociedad más pacífica, alejada de la gran crispación política actual en España.

En el año 2013, en la conocida como declaración de Berlín de la Quinta Conferencia Internacional de Ministros y Altos Funcionarios de la UNESCO encargados de la Educación Física y el Deporte se llegó a afirmar que la Educación Física en la escuela y en todas las demás instituciones educativas es el medio más efectivo para dotar a todos los niños y jóvenes de competencias, aptitudes, actitudes, valores, conocimientos y comprensión para su participación en la sociedad a lo largo de la vida. Toda una declaración de intenciones que debería fortalecernos. Nos ampara y nos dota de una responsabilidad especial al profesorado de Educación Física en estos tiempos de pandemia. No puede olvidarse el peso de esta materia en el curriculum educativo, y mucho menos ante crisis sanitarias como las que padecemos, en las que más que nunca se hace necesario incorporarla en las rutinas del alumnado como elemento disipador de inquietudes e incertidumbres $y$, a la postre, de interacción con sus iguales y mejora del bienestar físico y mental. Ahora nos toca reflexionar, compartir y actuar.

\section{Bibliografía}

Bourdieu, Pierre. 1992. "How can one be a sports fan?". En During (Ed.), The cultural studies reader, pp. 339-356. Londres: Routledge.

Brohm, Jean-Marie. 1982. Sociología política del deporte. México D.C.: Fondo de Cultura Económico.

García, Manuel; Puig, Nuria y Lagardera, Francisco. 1998. Sociología del Deporte. Madrid: Alianza Editorial.

Sánchez, Raúl y Moscoso, David. 2015. "How can one be a sports fan?» La contribución de Pierre Bourdieu al estudio social del deporte". Empiria. Revista de Metodología de Ciencias Sociales, 30, 161-180. 